\title{
Laboulbeniales (Fungi: Ascomycota) infection of bat flies (Diptera: Nycteribiidae) from Miniopterus schreibersii across Europe
}

\author{
Tamara Szentiványi ${ }^{1,2^{*}}$, Danny Haelewaters ${ }^{3,4}$, Walter P. Pfliegler ${ }^{5}$, Laura Clément ${ }^{1}$, Philippe Christe ${ }^{1 \dagger}$ (D)
} and Olivier Glaizot ${ }^{2+}$ (D)

\begin{abstract}
Background: Bat flies (Diptera: Nycteribiidae and Streblidae) are obligate, blood-sucking ectoparasites of bats with specialized morphology, life-cycle and ecology. Bat flies are occasionally infected by different species of Laboulbeniales (Fungi: Ascomycota), microscopic fungal ectoparasites belonging to three genera: Arthrorynchus spp. are restricted to the Eastern Hemisphere, while species of Gloeandromyces and Nycteromyces occur on Neotropical bat flies. Little is known about the distribution and host specificity of Arthrorynchus spp. on bat flies. In this study, we focused on sampling bat flies from the cave-dwelling bat species Miniopterus schreibersii. Bat and ectoparasite collection took place in Albania, Croatia, Hungary, Italy, Portugal, Slovakia, Spain and Switzerland. Flies were inspected for Laboulbeniales infections.
\end{abstract}

Results: Six hundred sixty seven bat flies of five species were collected: Nycteribia latreillii, N. pedicularia, N. schmidlii, Penicillidia conspicua, and P. dufourii. Laboulbeniales infection was observed on 60 specimens (prevalence $=9 \%$ ). Two Laboulbeniales species, Arthrorhynchus eucampsipodae and A. nycteribiae, were present on three bat fly species. All observations of A. eucampsipodae were on N. schmidlii, and A. nycteribiae was present on $P$. conspicua and $P$ dufourii. Arthrorhynchus eucampsipodae is, for the first time, reported from Slovakia and Spain. Arthrorhynchus nycteribiae represents a new country record for Portugal and Slovakia. There were no significant differences among infection rates in different countries. Females of $N$. schmidlii showed a higher infection rate than males with an observable trend $(P=0.0502)$. No sex differences in infection rate for $P$. conspicua and $P$. dufourii were detected. Finally, thallus density was significantly lower in N. schmidlii compared to P. conspicua and P. dufourii.

Conclusions: With this study, we contribute to the knowledge of the geographical distribution and host specificity of Laboulbeniales fungi associated with ectoparasitic bat flies within Europe. We discuss parasite prevalence and host specificity in the light of our findings and the available literature. Penicillidia conspicua is unambiguously the main host species for A. nycteribiae based on our and previous findings. Differences in parasite intensity and sexbiased infections of the fungi are possible depending on the species.

Keywords: Arthrorhynchus, Bat flies, Ectoparasites, Host specificity, Laboulbeniales, Nycteribiidae

\footnotetext{
* Correspondence: tamaraszentivanyi@gmail.com

†Philippe Christe and Olivier Glaizot contributed equally to this work.

'Department of Ecology and Evolution, University of Lausanne, Biophore,

$\mathrm{CH}-1015$ Lausanne, Switzerland

${ }^{2}$ Museum of Zoology, Palais de Rumine, Place de la Riponne 6, CH-1014

Lausanne, Switzerland

Full list of author information is available at the end of the article
}

(c) The Author(s). 2018 Open Access This article is distributed under the terms of the Creative Commons Attribution 4.0 International License (http://creativecommons.org/licenses/by/4.0/), which permits unrestricted use, distribution, and

reproduction in any medium, provided you give appropriate credit to the original author(s) and the source, provide a link to the Creative Commons license, and indicate if changes were made. The Creative Commons Public Domain Dedication waiver (http://creativecommons.org/publicdomain/zero/1.0/) applies to the data made available in this article, unless otherwise stated. 


\section{Background}

The distribution of parasites is shaped by the distribution of their hosts, although complete overlaps are infrequent. Hosts can lose their parasites or gain new ones when colonizing new areas [1,2]. Whether parasites are lost or gained is driven by a combination of abiotic and biotic factors. Abiotic factors, such as climate or habitat type can strongly affect parasite occurrence [3]. Biotic factors, for instance host behavior or immune response to parasitism, may be essential in determining factors in parasite distribution $[4,5]$. Studying geographical differences in parasite distributions is the first step in understanding how parasite loss or gain is shaped.

Bats represent the second largest mammal order with a worldwide distribution and have highly specific and diverse micro- and macroparasites [6], which can be subject to parasites of their own [7]. These multilevel trophic systems may be shaped by many parameters, such as the ecology, immunology, behavior and sex of the bat hosts as well as their parasites (e.g. $[4,8,9]$ ).

This study focuses on Miniopterus schreibersii, a cave-dwelling bat which is widely distributed across southern Europe, Asia Minor and North Africa, and represents the only European member of its genus [10]. Miniopterus schreibersii hosts a myriad of highly specific parasites as for example Spinturnix psi mites (Acari: Mesostigmata: Spinturnicidae), Nycteribia schmidlii and Penicillidia conspicua bat flies (Diptera: Hippoboscoidea: Nycteribiidae), or Polychromophilus melanipherus blood parasites (Alveolata: Apicomplexa: Plasmodiidae) [9, 11, 12]. Additionally, non-specific ectoparasites, such as the bat fly species Penicillidia dufourii, Nycteribia latreillii and $N$. pedicularia, can parasitize $M$. schreibersii. Even though these non-specific associations are considered the result of accidental host choice by the parasites, they cannot be considered rare [9]. Altogether, M. schreibersii represents an outstanding target species in parasitology research.

Bat flies are obligate blood-sucking ectoparasites of bats belonging to two families, the Nycteribiidae and the Streblidae. In Europe, 16 nycteribiid and one streblid species have been reported so far [9]. The morphology and life-cycle of bat flies are unique among Diptera. Nycteribiids are wingless and possess reduced ocelli, both being adaptations for living in the fur of their hosts. Bat flies give birth to a single third-instar larva (larviposition) on the roost wall of their hosts. Before larviposition, the larva develops in the uterus-like organ of the female, nourished by milk-glands. The larva immediately pupates after larviposition and the emergence of imagoes from pupae is influenced by the presence of bats; after emergence bat flies actively search for bat hosts [6].

Laboulbeniales are ectoparasitic fungi that associate with representatives of three subphyla of Arthropoda: Chelicerata, Myriapoda and Hexapoda [13]. Of all described Laboulbeniales species, $80 \%$ are associated with Coleoptera and $10 \%$ with Diptera. The rest occur on many other different taxa, belonging to Arachnida, Diplopoda and Hexapoda [13]. The Laboulbeniales are different from most other fungal groups because they lack hyphae and instead form microscopic fruiting bodies or thalli as a result of determinate growth. Most Laboulbeniales are moderately to extremely host-specific. Many members of the order are associated with a single host species or several species of a same genus. Some species exhibit position specificity and are found on determined parts of their host's integument [14]. What drives host specificity in nature is unknown. Ecological specificity is the last but most interesting level; shifts between phylogenetically unrelated hosts that share the same microhabitat is a significant trigger for speciation [15-17]. Three genera and eight species of Laboulbeniales are known from bat flies [7, 18], with the potential of many undescribed species, especially in the Neotropics [19]. The genera Gloeandromyces and Nycteromyces are reported on streblid bat flies from Central and South America. Arthrorhynchus is apparently restricted to the Eastern Hemisphere and has only been reported from Nycteribiidae. Four species are known: Arthrorhynchus acrandros, A. cyclopodiae, A. eucampsipodae and A. nycteribiae (although A. acrandros is disputed [7]). Arthrorhynchus nycteribiae has been most widely reported [7, 19]. It is known in Europe (Austria, Bulgaria/Slovakia, Croatia, the Czech Republic, "Czecho-slovakia" [sic.], Denmark, France, Hungary, Italy, Poland, Romania, Russia, Serbia, Spain, Sweden, Switzerland and the Netherlands), Africa (Kenya and Zambia), Asia (Sri Lanka) and Oceania (Australia).

In a recent study, 1494 bat flies (11 spp.) from 1594 bats (28 spp.) collected in Europe were screened for the presence of Laboulbeniales fungi [7]. Many bat flies parasitized by these fungi have been collected from $M$. schreibersii. The prevalence of Laboulbeniales on bat flies from this species was highly disparate among bat fly species. Nycteribia schmidlii had a parasite prevalence of 3.1\% ( $n=147)$, and was infected by both Arthrorhynchus eucampsipodae and A. nycteribiae. Penicillidia conspicua had a prevalence of $23.1 \%(n=142)$; only $A$. nycteribiae was found. All $P$. dufourii from $M$. schreibersii were found to be uninfected $(n=22)$.

In the present study, we expanded capturing efforts of M. schreibersii to focus on Laboulbeniales infections of specific versus generalist bat flies. Using this tripartite system, we attempted to assess parasite distributions within and between host populations.

\section{Methods}

\section{Collection of bats and bat flies}

Bats were captured from April through September in 2009-2016, using mist nets and harp-traps, placed in 
front of caves where M. schreibersii colonies occur. Sampling took place in Albania, Croatia, Hungary, Italy, Portugal, Slovakia, Spain and Switzerland (Fig. 1). Exact localities are given in Additional file 1: Table S1. Age, sex, and morphological characteristics were collected for most individuals. Bat flies were removed with forceps and placed in $70-90 \%$ ethanol. Bats were released immediately after processing in the vicinity of the capture site.

Bat fly species and sex were determined following Theodor's key (1967) [21]. Voucher bat fly specimens are deposited under the accession number 16CH12-XB07 at the Museum of Zoology, Lausanne, Switzerland.

\section{Collection and identification of Laboulbeniales}

The presence or absence of Laboulbeniales was determined using a stereomicroscope (Leica M205C, Leica Mcrosystems AG, Heerbrugg, Switzerland). For each infected bat fly, the total number of Laboulbeniales thalli was counted. Thalli were removed from the host at the point of attachment with an entomological pin and slide-mounted in Amman's solution for identification [22]. Identification was based on the original descriptions and drawings by Thaxter [23] and recent amendments by Haelewaters et al. [7]. Slides will be deposited at the mycology herbarium of Ghent University, Belgium (Ghent).

\section{Statistical analyses}

Fisher's exact tests were used for prevalence comparison among countries, bat fly species and sexes. In addition, Mood's median tests were performed to compare the median thallus density and bootstrap tests were used to compare mean thallus density of Laboulbeniales among infected bat fly hosts (based on 1000 bootstrap replications), performed in Quantitative Parasitology v.3.0 [24].

\section{Results}

\section{Bat flies and Laboulbeniales}

We collected 667 bat flies from 270 M. schreibersii bats. Five bat fly species were encountered: $N$. schmidlii $(n=468), P$. conspicua $(n=144), P$. dufourii $(n=52), N$. pedicularia $(n=2)$ and Nycteribia latreillii $(n=1)$. Of all bat flies, 60 specimens were infected with Laboulbeniales fungi (prevalence of 9\%). Nycteribia latreillii and N. pedicularia were represented in very low sample numbers and were uninfected with Laboulbeniales, therefore we excluded them from further analyses, figures and tables. Arthrorhynchus eucampsipodae was found in Hungary, Slovakia and Spain (Table 1). All observations of A. eucampsipodae were made on a single bat fly host, Nycteribia schmidlii. Additionally, we reported $A$. nycteribiae from five countries: Croatia, Hungary, Portugal, Slovakia and Spain (Table 1). Hosts for A. nycteribiae were P. conspicua and P. dufourii.

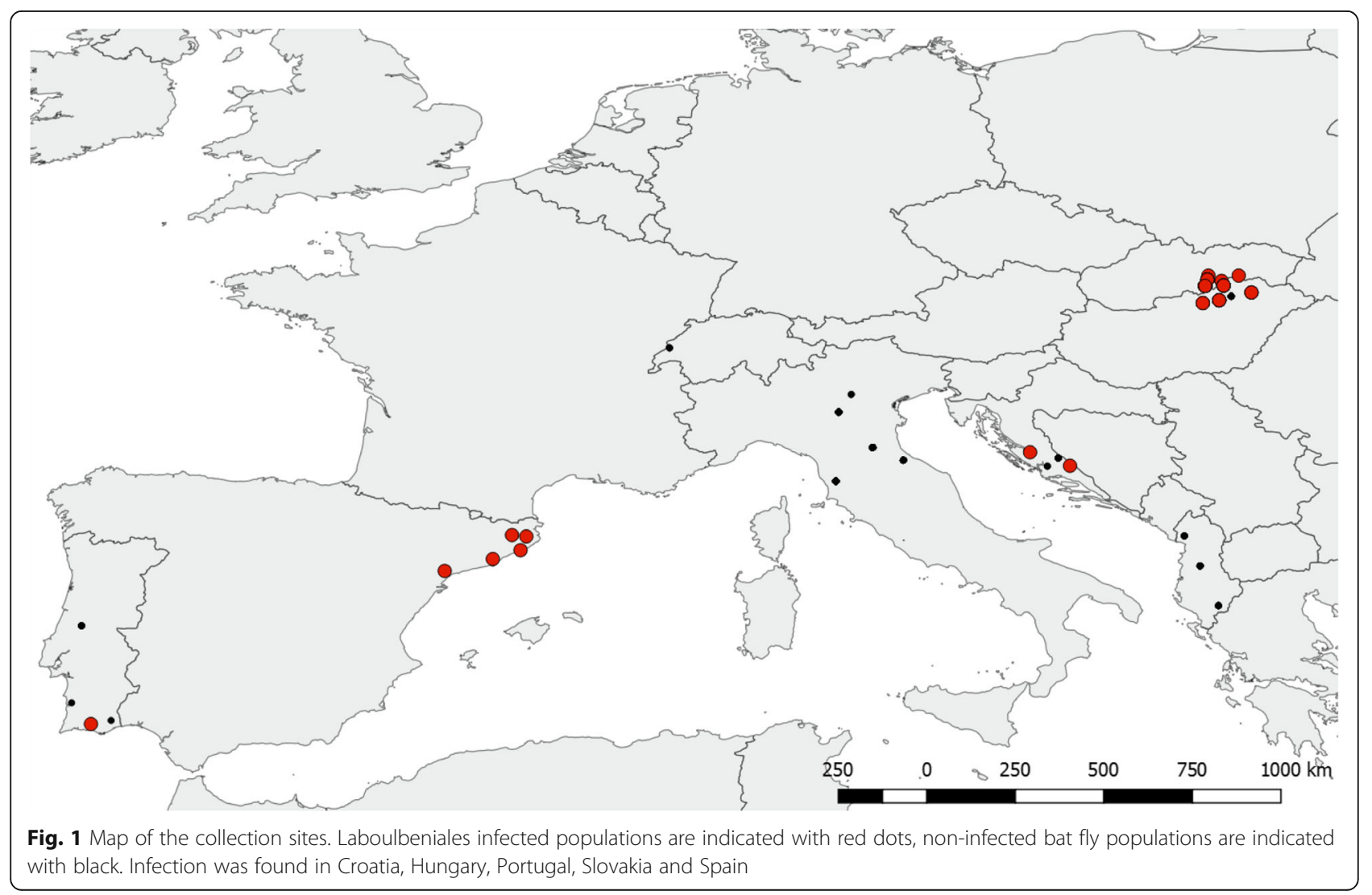


Table 1 Host associations of Arthrorhynchus eucampsipodae and A. nycteribiae reported during this study

\begin{tabular}{|c|c|c|c|c|c|c|}
\hline Country & $\begin{array}{l}\text { No. of collected flies } \\
\text { (overall prevalence in \%) }\end{array}$ & No. of infected flies & $\begin{array}{l}\text { No. of Arthrorhynchus } \\
\text { eucampsipodae }\end{array}$ & Host & $\begin{array}{l}\text { No. of Arthrorhynchus } \\
\text { nycteribiae }\end{array}$ & Host \\
\hline Albania & $32(0)$ & 0 & - & & - & \\
\hline Croatia & $17(11.7)$ & 2 & - & & 2 & PCON \\
\hline Hungary & $82(15.8)$ & 13 & 3 & $\mathrm{NSCH}$ & 10 & PCON, PDUF \\
\hline Italy & $327(0)$ & 0 & - & - & - & \\
\hline Portugal & $11(9)$ & 1 & - & & $1^{\mathrm{a}}$ & PCON \\
\hline Slovakia & $152(25.6)$ & 39 & $19^{\mathrm{a}}$ & $\mathrm{NSCH}$ & $20^{b}$ & PCON, PDUF \\
\hline Spain & $42(11.9)$ & 5 & $1^{\mathrm{a}}$ & $\mathrm{NSCH}$ & 4 & PCON \\
\hline Switzerland & $4(0)$ & 0 & - & & - & \\
\hline Total & $667(8.9)$ & 60 & 23 & & 37 & \\
\hline
\end{tabular}

Abbreviations: NSCH Nycteribia schmidlii, PCON Penicillidia conspicua; PDUF Penicillidia dufourii

${ }^{\text {a}}$ First country record

${ }^{\mathrm{b}}$ First undoubtful country record

The presence of A. eucampsipodae is reported here, for the first time, from Slovakia and Spain. Additionally the presence of $A$. nycteribiae is also a new record from Portugal and the first undoubtful record from Slovakia.

\section{Prevalence rate in different countries}

In Albania, Italy and Switzerland, Laboulbeniales infection was not detected among the 361 collected specimens of Nycteribia schmidlii, Penicillidia conspicua and P. dufourii. The highest parasite prevalence was observed in Slovakia (25.6\%). We found the lowest overall parasite prevalence in Portugal (10\%, only P. conspicua sampled). In Croatia, Hungary and Spain, overall fungal prevalence was $11.7 \%$, $15.8 \%$ and $11.9 \%$, respectively. There were no significant differences in parasite prevalence between the different countries.

\section{Parasite prevalence and host specificity}

Of the 468 collected $N$. schmidlii, 23 flies were infected (4.9\%) with Laboulbeniales. We sampled 52 specimens of $P$. dufourii of which 4 individuals carried Laboulbeniales $(7.7 \%)$. Of 144 P. conspicua specimens, 33 were infected (22.9\%). Penicillidia conspicua had a significantly higher parasite prevalence compared to the other two species (Fisher's exact test, $P<0.0001$ ). Infection by A. eucampsipodae was found exclusively on N. schmidlii, while $A$. nycteribiae infection was detected only on Penicillidia species.

\section{Differences in parasite prevalence between female and male bat flies}

Of 269 females and 199 males of N. schmidlii, we found 18 infected females and 5 infected males, which shows a marginally significant trend in the infection between the sexes (6.7 and 2.5\%, respectively; Fisher's exact test, $P=0.0502)$. Of 81 females and 63 males of $P$. conspicua, 21 females and 12 males were infected
(25.9 and 19\%, respectively; Fisher's exact test, $P=$ 0.424) with Laboulbeniales. Of $P$. dufourii, 25 females and 27 males were collected and only two individuals were infected for each sex (8 and 7.4\%, respectively; Fisher's exact test, $P=1.0$; Fig. 2), therefore the prevalence is not significantly different between the sexes, neither in $P$. conspicua, nor in $P$. dufourii.

\section{Thallus density of Laboulbeniales on bat flies}

The mean thallus density $( \pm$ SD) per specimen was $7.8 \pm$ 10.6 for $N$. schmidlii $(n=23), 35.6 \pm 31$ for P. conspicua $(n=33)$ and $35 \pm 16.3$ for $P$. dufourii $(n=4)$. Nycteribia schmidlii, which was infected with A. eucampsipodae, showed significantly lower thallus density when median intensities were compared among the three bat fly species (Fig. 3, Table 2; Mood's median test, $P<0.0001$ ). The thallus density was not significantly different between female and male bat flies (Table 2), neither for $N$. schmidlii (Bootstrap two-sample t-test, $P=0.223$, female: $8.8 \pm 11.7$, male: $4.2 \pm 3.5$ ) nor for $P$. conspicua (Bootstrap 2-sample t-test, $P=0.499$, female: $38.1 \pm$ 35.2, male: $31.4 \pm 22.4$ ). Penicillidia dufourii was excluded from this analysis due to low sample size. Nycteribia schmidlii females $(n=18)$ showed a mean thallus density of 8.8 , while males $(n=5)$ had a mean thallus density of 4.2. Mean thallus density on P. conspicua was 38.1 for females $(n=21)$ and 31.4 for males $(n=12)$ (Table 2).

\section{Discussion}

Geographical distribution, host range, and prevalence of Laboulbeniales

The geographical distribution and host range of bat-fly associated Laboulbeniales in Europe has been reported by several studies $[7,20,25,26]$. Our study presents additional occurrence data focusing on the tripartite system of the M. schreibersii cave-dwelling bat, its ectoparasitic 


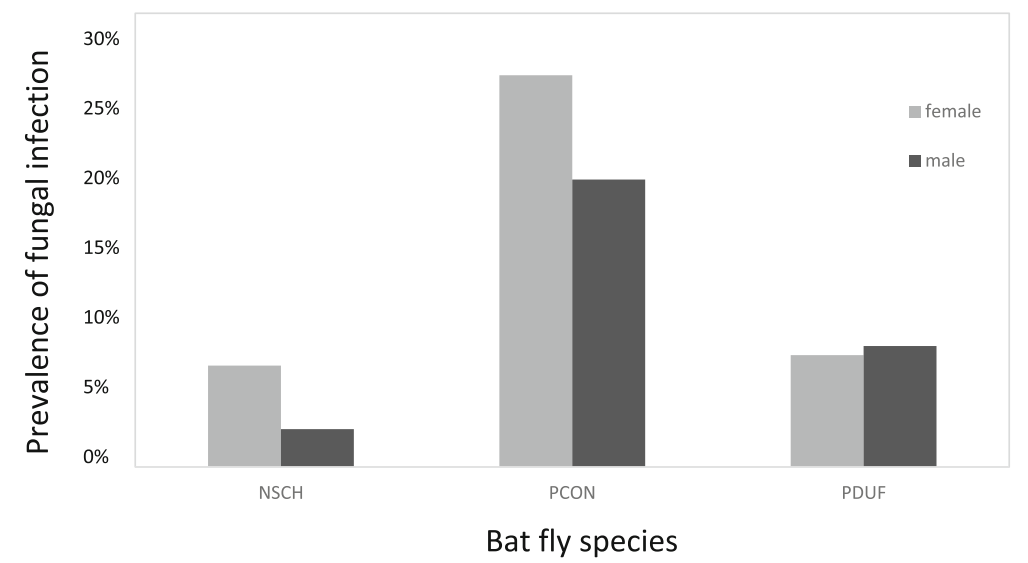

Fig. 2 The infection rates of male and female bat flies across three species, Nycteribia schmidlii ( $n=468 ; 269$ females and 199 males), Penicillidia conspicua ( $n=144 ; 81$ females and 63 males), and P. dufourii ( $n=52 ; 25$ females and 27 males). Female flies are represented by gray, males with black bars. Prevalence rate of sexes is given (in percentage) for each category. Abbreviations: NSCH, Nycteribia schmidlii; PCON, Penicillidia conspicua; PDUF, Penicillidia dufourii

bat flies and their Laboulbeniales ectoparasites. Our findings agree with previously reported host species for these fungi $[7,19]$. To date, $P$. conspicua has only been reported as host for A. nycteribiae, while $P$. dufourii and N. schmidlii are host for both A. eucampsipodae and A. nycteribiae.

Blackwell [20] reported the prevalence of Arthrorhynchus species to be $2.2 \%(n=2517)$. Regarding the bat fly species discussed in our study, she found parasite prevalences of $2.5 \%$ on $N$. schmidlii $(n=316), 18.6 \%$ on P. conspicua $(n=86)$ and $0.7 \%$ on $P$. dufourii $(n=289)$. Haelewaters et al. [7] reported a total prevalence of $3 \%$ on all screened bat flies $(n=1494)$ but the parasite prevalence varied depending on the host species. These and our results allow us

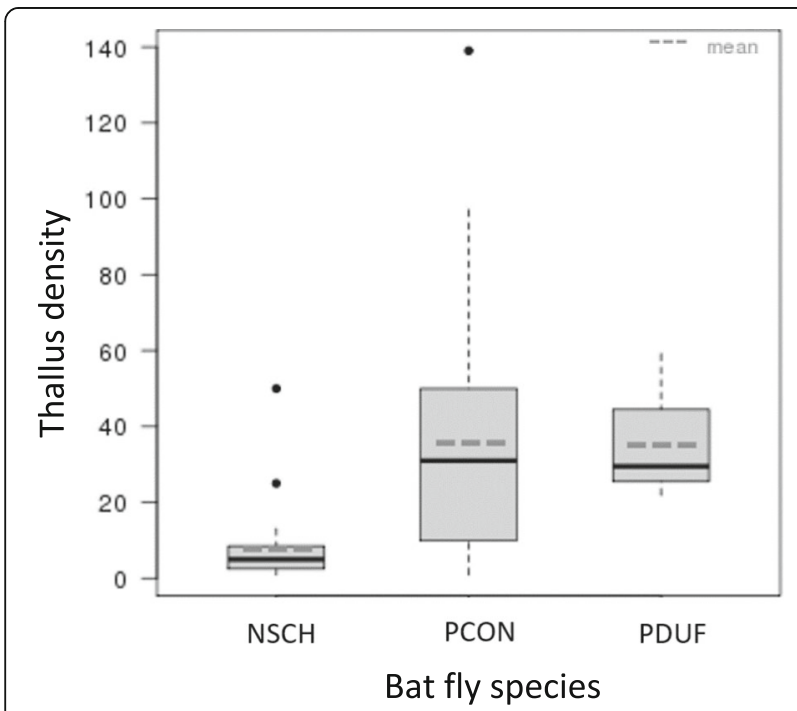

Fig. 3 Thallus density of Laboulbeniales on Nycteribia schmidlii $(n=$ 23), Penicillidia conspicua $(n=33)$ and P. dufourii $(n=4)$. Significant difference is observed between $N$. schmidlii and Penicillidia spp. (Mood's median test, $P<0.0001$ ) to suggest that these low (N. schmidlii, P. dufourii) to moderate $(P$. conspicua) infection rates in these species are not particularly variable.

Based on our study and the recent work by Haelewaters et al. [7], A. eucampsipodae seems to be highly specific towards N. schmidlii. However, Blackwell [20] reported other host species for $A$. eucampsipodae with prevalences ranging between $0.3-8.3 \%$. Although A. eucampsipodae displays preferences for $N$. schmidlii, strict host specificity does not seem to be the rule for this Laboulbeniales species. The same specificity pattern is observed for $A$. nycteribiae $[7,19]$.

Based on our results, we can conclude that Penicillidia dufourii is merely a secondary host species for $A$. nycteribiae compared to $P$. conspicua. This confirms findings by Haelewaters et al. [7] who reported a prevalence for A. nycteribiae of $25 \%$ on P. conspicua $(n=152)$, whereas on $P$. dufourii prevalence was much lower $(2.0 \%$, $n=102)$. In addition, Blackwell's [20] data, also show that $P$. conspicua has the highest prevalence with $A$. nycteribiae $(18.6 \%, n=86)$. Taken together, $P$. conspicua is unambiguously the main host species for A. nycteribiae, but this fungus probably has the capacity to also grow on many other bat fly hosts.

Although Laboulbeniales prevalence on bat flies varied among countries, we did not find significant differences. Since infection rates can be influenced by habitat type on a smaller geographical level, such as differences between wet or dry habitats (see [26] and references therein), future work should focus on identifying factors that shape the distribution of infection.

\section{Prevalence of Laboulbeniales between bat fly sexes}

In parasitological studies, it is widely observed that different sexes often show different infection rates throughout 
Table 2 Mean and median thallus density of Nycteribia schmidlii and Penicillidia conspicua within species and between sexes

\begin{tabular}{|c|c|c|c|c|c|c|c|c|}
\hline \multirow[t]{2}{*}{ Species } & \multicolumn{2}{|l|}{ Female } & \multicolumn{2}{|l|}{ Male } & \multicolumn{4}{|c|}{ Total } \\
\hline & Mean density $(n)$ & SD & Mean density $(n)$ & SD & $n$ & Mean density & Median density & SD \\
\hline $\mathrm{NSCH}$ & $8.8(18)$ & 11.7 & $4.2(5)$ & 3.5 & 23 & 7.87 & 5.0 & 10.6 \\
\hline PCON & $38.1(21)$ & 35.2 & $31.4(12)$ & 22.4 & 33 & 35.6 & 31 & 31 \\
\hline PDUF & - & - & - & - & 4 & 35 & 27.5 & 16.3 \\
\hline
\end{tabular}

Abbreviations: NSCH Nycteribia schmidlii, PCON Penicillidia conspicua, SD standard deviation

several taxa $[8,27,28]$. Recently, it was found that among bat flies females are more likely to be infected with Arthrorhynchus spp. compared to males [7]. In our study, we only found a trend supporting this observation in the case of $N$. schmidlii $(P=0.0502)$, but no support was found for P. conspicua and $P$ dufourii (Fig. 2). A commonly reported species of Laboulbeniales for which infection patterns can be significantly different between male and female hosts is Hesperomyces virescens, a parasite of ladybirds (Coleoptera: Coccinellidae). Sexual differences (e.g. prevalence and/or position specificity) in $H$. virescens infection on Harmonia axyridis ladybirds are presumed to be the result of host mating behavior [29-31]. Regarding bat flies, females are known to live longer [32]. Pregnant bat flies are significantly larger than male flies, accounting for more integument surface, and have fat reserves organized as lobes in their haemolymph, presenting higher nutritional resources [33].

Different sexes can exhibit different levels of parasite resistance $[27,33,34]$. These differences are most commonly explained by variances in hormone levels between sexes, for example steroid reproductive hormones [28]. In conclusion, sex bias in parasitism can occur also as a consequence of the different immune status of the hosts.

\section{Thallus density of Laboulbeniales on bat flies}

Thallus density of Laboulbeniales can vary over time and can be different between host sexes and among host body parts [26, 35-37]. We found significantly higher thallus density on $P$. conspicua and $P$. dufourii compared to $N$. schmidlii $(P<0.001)$. This difference could be linked to host size, since both species of Penicillidia can reach body lengths of $3.4-4 \mathrm{~mm}$, while $N$. schmidlii is much smaller (2-2.25 mm; [21]). However, Arthrorhynchus spp. also vary in size. Arthrorhynchus eucampsipodae (which parasitizes $N$. schmidlii) measures 375-550 $\mu \mathrm{m}$ in length (receptacle + cell VI + perithecium), while A. nycteribiae is generally longer, $390-750 \mu \mathrm{m}[23,38]$.

\section{Conclusions}

During this study, we collected and analyzed the occurrence of Arthrorhynchus spp. in a wide range of geographical distributions within Europe on the cave-dwelling bat species, Miniopterus schreibersii. Five bat fly species were collected in eight countries, on which three species showed fungal infections, each with a different parasite prevalence. Prevalence can differ among host species and between host sexes. Arthrorhynchus eucampsipodae was only reported on N. schmidlii. In addition, A. nycteribiae was observed on two Penicillidia species, of which $P$. conspicua appeared to be the "main host" for this fungus, while $P$. dufourii is considered a secondary or accidental host. Our work has also resulted in new country records: $A$. eucampsipodae is newly reported from Slovakia and Spain, while A. nycteribiae is newly reported from Portugal and represents the first undoubtful record for Slovakia.

\section{Additional files}

\section{Additional file 1: Table S1. Additional data on bat, bat fly and} Laboulbeniales occurrence. The exact location of parasite collection as well as sex and infection data of bat flies and fungus are shown. (XLSX $60 \mathrm{~kb}$ )

\section{Acknowledgements}

We are grateful to Péter Estók, Eléonore Genzoni, Adrià López-Baucells, Jorge Palmeirim, Igor Pavlinic, Dino Scaravelli, Martin Ševčík, Philippe Théou and Fardo Witsenburg, for their help during sample collection. The authors are grateful for the anonymous reviewers for their helpful comments on a draft of this manuscript.

\section{Funding}

$\mathrm{DH}$ gratefully acknowledges funding for his bat flies-Laboulbeniales work from the following sources: Harvard University Herbaria (Fernald Fund), David Rockefeller Center for Latin American Studies (Summer Research Travel Grants, Term-Time Research Fellowship), Smithsonian Tropical Research Institute (Short-Term Research Fellowship), and Mycological Society of America (Graduate Fellowship, Robert W. Lichtwardt Student Research Award). WPP was supported through the ÚNKP-16-4-IV New National Excellence Program of the Ministry of Human Capacities of Hungary.

\section{Availability of data and materials}

Datasets supporting the conclusions of this article are included within the article and its additional file. Voucher specimens of bat flies are deposited at Museum of Zoology, Lausanne, Switzerland under the accession numbers: $16 \mathrm{CH} 12-\mathrm{XB} 07$

\section{Authors' contributions}

TS initiated the study and identified the bat fly parasite specimens. WPP identified fungal specimens. LC, TS, PC and OG participated in parasite collection. TS, DH, WPP, PC and OG contributed toward writing the first draft of the manuscript. All authors read and approved the final manuscript.

\section{Ethics approval}

Animal capture was conducted according to the Swiss Animal Legislation (legislation number 2964). 


\section{Competing interests}

The authors declare that they have no competing interests.

\section{Publisher's Note}

Springer Nature remains neutral with regard to jurisdictional claims in published maps and institutional affiliations.

\section{Author details}

'Department of Ecology and Evolution, University of Lausanne, Biophore, CH-1015 Lausanne, Switzerland. ${ }^{2}$ Museum of Zoology, Palais de Rumine, Place de la Riponne 6, CH-1014 Lausanne, Switzerland. ${ }^{3}$ Department of Organismic and Evolutionary Biology, Harvard University, Cambridge, Massachusetts 02138, USA. ${ }^{4}$ Farlow Reference Library and Herbarium of Cryptogamic Botany, Harvard University, 22 Divinity Avenue, Cambridge, Massachusetts 02138, USA. ${ }^{5}$ Department of Biotechnology and Microbiology, University of Debrecen, Egyetem tér 1, Debrecen H4032, Hungary.

Received: 6 February 2018 Accepted: 28 May 2018

Published online: 05 July 2018

\section{References}

1. MacLeod CJ, Paterson AM, Tompkins DM, Duncan RP. Parasites lost - do invaders miss the boat or drown on arrival? Ecol Lett. 2010;13:516-27.

2. Strona G. Past, present and future of host-parasite co-extinctions. Int J Parasitol Parasites Wildl. 2015:4:431-41.

3. Krasnov BR, Shenbrot Gl, Medvedev SG, Vatschenok VS, Khokhlova IS. Hosthabitat relations as an important determinant of spatial distribution of flea assemblages (Siphonaptera) on rodents in the Negev Desert. Parasitology. 1997:114:159-73.

4. Reckardt K, Kerth G. Roost selection and roost switching of female Bechstein's bats (Myotis bechsteinii) as a strategy of parasite avoidance. Oecologia. 2007;154:581-8

5. Tschirren B, Bischoff LL, Saladin V, Richner H. Host condition and host immunity affect parasite fitness in a bird-ectoparasite system. Funct Ecol. 2007;21:372-8

6. Dick CW, Patterson BD. Bat flies: obligate ectoparasites of bats. In: Morand S, Krasnov BR, Poulin R, editors. Micromammals macroparasites. From evolutoionary ecology to management. New York: Springer; 2006. p. 179-94.

7. Haelewaters D, Pfliegler WP, Szentiványi T, Földvári M, Sándor AD, Barti L, et al. Parasites of parasites of bats: Laboulbeniales (Fungi: Ascomycota) on bat flies (Diptera: Nycteribiidae) in central Europe. Parasit Vectors. 2017;10:96.

8. Christe P, Glaizot O, Evanno G, Bruyndonckx N, Devevey G, Yannic G, et al. Host sex and ectoparasites choice: Preference for, and higher survival on female hosts. J Anim Ecol. 2007;76:703-10.

9. Szentiványi T, Földvàri M, Estók P. Checklist of host associations of European bat flies (Diptera: Nycteribiidae, Streblidae). Zootaxa. 2016;4205:101.

10. Hutson AM, Aulagnier S, Benda P, Karataş A, Palmeirim J, Paunović M. Miniopterus schreibersii. IUCN Red List Threat. Species. 2008. Accessed 04 Feb 2018.

11. Dew BB. Seasonal variation of Polychromophilus melanipherus (Sporozoa: Haemoproteidae) in the bent-winged bat Miniopterus schreibersii (Chiroptera) in New South Wales. Parasitology. 1970;61:161-6.

12. Estrada-Pena A, Serra-Cobo J. The Acarina and Nycteribidia zones of Miniopterus schreibersi Kuhl (Mammalia: Chrioptera) in the Northeast of Spain. Folia Parasitol. 1991;38:345-54.

13. Weir A, Hammond PM. Laboulbeniales on beetles: host utilization patterns and species richness of the parasites. Biodivers Conserv. 1997:6:701-19.

14. Goldmann L, Weir A. Position specificity in Chitonomyces (Ascomycota, Laboulbeniomycetes) on Laccophilus (Coleoptera, Dytiscidae): a molecular approach resolves a century-old debate. Mycologia. 2012;104:1143-58.

15. Rossi W. New species of Laboulbenia from Ecuador, with evidence for host switch in the Laboulbeniales. Mycologia. 2011;103:184-94.

16. De Kesel A, Haelewaters D. Laboulbenia slackensis and L. littoralis sp. nov. (Ascomycota, Laboulbeniales), two sibling species as a result of ecological speciation. Mycologia. 2014;106:407-14

17. Pfliegler WP, Báthori F, Haelewaters D, Tartally A. Studies of Laboulbeniales on Myrmica ants (III): myrmecophilous arthropods as alternative hosts of Rickia wasmannii. Parasite. 2016:23:50.

18. Haelewaters D, Verhaeghen SJC, Gonzàles TAR, Vega JAB, Saucedo RW. New and interesting Laboulbeniales from Panama and neighboring areas. Nov Hedwigia. 2017;105:267-99.
19. Walker MJ, Dorrestein A, Camacho JJ, Meckler LA, Silas KA, Hiller T, et al. A tripartite survey of hyperparasitic fungi associated with ectoparasitic flies on bats (Mammalia: Chiroptera) in a neotropical cloud forest in Panama. Parasite. 2018:25:19.

20. Blackwell M. Incidence, host specificity, distribution, and morphological variation in Arthrorhynchus nycteribiae and A. eucampsipodae (Laboulbeniomycetes). Mycologia. 1980;72:143-58.

21. Theodor O. An illustrated catalogue of the Rothschild collection of Nycteribiidae in the British Museum (Natural History), with keys and short descriptions for the identification of subfamilies, genera, species and subspecies. London: British Museum (Natural History); 1967.

22. Haelewaters D, Zhao SY, De Kesel A, Handlin RE, Royer IR, Farrell BD, et al. Laboulbeniales (Ascomycota) of the Boston Harbor Islands I: Species parasitizing Coccinellidae and Staphylinidae, with comments on typification. Northeast Nat. 2015;22:459-77.

23. Thaxter R. Contribution toward a monograph of the Laboulbeniaceae. Part II. Mem Am Acad Arts Sci. 1908;13:217-469.

24. Rózsa L, Reiczigel J, Majoros G. Quantifying parasites in samples of hosts. J Parasitol. 2000;86:228-32

25. Balcells RE. Quirópteros de cuevas catalanas: Campaña de 1952-53. Speleon. 1954:5:105-10.

26. Samsinakova A. Beitráge zur Kenntnis der entomophagen Pilze auf den Nycteribiiden. Zool List. 1960;9:237-8. (In Czech)

27. Markó B, Csata E, Eros K, Német E, Czekes Z, Rózsa L. Distribution of the myrmecoparasitic fungus Rickia wasmannii (Ascomycota: Laboulbeniales) across colonies, individuals, and body parts of Myrmica scabrinodis. Invertebr Pathol. 2016;136:74-80.

28. Zuk M, McKean KA. Sex differences in parasite infections: patterns and processes. Int J Parasitol. 1996;26:1009-24.

29. Morand S, De Bellocq JG, Stanko M, Miklisová D. Is sex-biased ectoparasitism related to sexual size dimorphism in small mammals of Central Europe? Parasitology. 2004;129:505-10.

30. Welch VL, Sloggett JJ, Mary Webberley K, Hurst GDD. Short-range clinal variation in the prevalence of a sexually transmitted fungus associated with urbanisation. Ecol Entomol. 2001:26:547-50.

31. Nalepa CA, Weir A. Infection of Harmonia axyridis (Coleoptera: Coccinellidae) by Hesperomyces virescens (Ascomycetes: Laboulbeniales): Role of mating status and aggregation behavior. J Invertebr Pathol. 2007;94:196-203.

32. Marshall AG. The life cycle of Basilia hipsida Theodor 1967 (Diptera: Nycteribiidae) in Malaysia. Parasitology. 1970;61:1-18.

33. Rogers DJ, Randolph SE. Metabolic strategies of male and female tsetse (Diptera: Glossinidae) in the field. Bull Entomol Res. 1978;68:639.

34. Stoehr AM, Kokko H. Sexual dimorphism in immunocompetence: What does life-history theory predict? Behav Ecol. 2006;17:751-6.

35. Salvador A, Veiga JP, Martin J, Lopez P, Abelenda M, Puerta M. The cost of producing a sexual signal: testosterone increases the susceptibility of male lizards to ectoparasitic infestation. Behav Ecol. 1996;7:145-50.

36. De Kesel A. Relative importance of direct and indirect infection in the transmission of Laboulbenia slackensis (Ascomycetes, Laboulbeniales). Belgian J Bot. 1995:128:124-30.

37. Riddick EW, Schaefer PW. Occurrence, density, and distribution of parasitic fungus Hesperomyces virescens (Laboulbeniales: Laboulbeniaceae) on multicolored Asian lady beetle (Coleoptera: Coccinellidae). Ann Entomol Soc Am. 2005;98:615-24.

38. Thaxter R. Contribution towards a monograph of the Laboulbeniaceae. Mem Am Acad Arts Sci. 1896;12:187-429.

\section{Ready to submit your research? Choose BMC and benefit from}

- fast, convenient online submission

- thorough peer review by experienced researchers in your field

- rapid publication on acceptance

- support for research data, including large and complex data types

- gold Open Access which fosters wider collaboration and increased citations

- maximum visibility for your research: over $100 \mathrm{M}$ website views per year

\section{At BMC, research is always in progress.}

Learn more biomedcentral.com/submissions 